\title{
Las tareas escolares: representaciones de los docentes de lenguas
}

\section{Homework: Representations of Language Teachers}

\author{
Jaime Ruiz Vega \\ Myriam Cecilia Castillo Perilla \\ Álvaro William Santiago Galvis ${ }^{1 凶}$
}

\section{Resumen}

El artículo presenta los resultados que se obtuvieron en el desarrollo del proyecto “La movilización discursiva de valores sociales asociados a la entidad léxica tarea escolar en la educación básica y media en Bogotá" (DLE-361-13), que tuvo como objetivo identificar y analizar las concepciones que de las tareas escolares tienen los docentes de educación básica y media de Bogotá. En primera instancia, se da cuenta de la metodología que estructuró el trabajo, la cual se sustenta en las orientaciones de la semántica de los posibles argumentativos (SPA); luego, se ofrece el análisis de los datos obtenidos en lo que respecta al núcleo de la entidad léxica tarea escolar, los estereotipos y los valores asociados a estos, tanto en el discurso lexicográfico como en el de los docentes; finalmente, se establece la comparación entre el discurso lexicográfico y el de los docentes con el fin de identificar los elementos comunes de las dos representaciones y mostrar los despliegues inéditos del significado léxico obtenidos en los datos de los encuestados.

\section{Palabras clave}

Tarea escolar, entidad léxica, núcleo, estereotipos, valores sociales, representación lingüística, representación social.

\section{Abstract}

This article presents the results obtained in the development of a project on the discursive motivation of social values associated to the lexical entity of homework in primary and secondary education in Bogotá, DLE-361-13, which principally sought to identify and analyse the concepts of the homework assignments of primary and secondary school teachers. Firstly, one realises that the methodology that structured the work is based on guidance from the Posibles Argumentativos -SPA-; then it offers an analysis of the data obtained with respect to the core of the lexical entity of homework, stereotypes, and the associated values of these things, both in the lexicographical and in the teachers. Finally, it establishes the comparison between the lexicographical discourse and the teacher discourse with the aim of identifying the common elements of the two representations and showing the unedited deployment of lexical meaning obtained from the data of the surveyed.

Key words

Homework, lexical entity, core, stereotypes, social values, linguistic representation, social representation.

Artículo recibido el 19 de diciembre de 2014 y aprobado el 7 de abril de 2015

1 Universidad Pedagógica Nacional, Bogotá, Colombia. Profesores del Departamento de Lenguas, integrantes del Grupo de Investigación en Pedagogía, Lenguaje y Comunicación, GIPELEc. Correos electrónicos: mcastillo@pedagogica.edu.co; asantiago@pedagogica.edu.co; jruiz@pedagogica.edu.co 
Dada la naturaleza compleja del hecho educativo como tal, y del sistema que lo orienta formalmente, son varios los aspectos de este último y, de manera específica, de los programas de formación - sean estos de la educación superior o de los diferentes ciclos de la educación básica y media- que requieren estudio y seguimiento permanentes para alcanzar una mejor formación de los ciudadanos de esta sociedad y de los futuros profesionales. A manera de ejemplo, se pueden enunciar tres de estos aspectos, importantes en todo nivel del sistema educativo colombiano: la evaluación, la interacción y las tareas escolares. Las tareas, entonces, se constituyen en un aspecto de los procesos educativos que en la actualidad se ha convertido en objeto de debate, tanto académico como legal, a tal punto que se han generado propuestas, tan extremas como las de algunos legisladores, que buscan eliminarlas del ámbito escolar; así como prácticas escolares que llevan a la reacción de educandos y padres de familia que llegan a calificarlas de actividades sin sentido.

En este orden de ideas, el proyecto DLE-361-13 se orientó hacia la identificación y el análisis de las concepciones que de las tareas escolares tienen los docentes de la educación básica y media de Bogotá. $\mathrm{Si}$ existe un interés en modificar e, inclusive, en suprimir las tareas es prioritario dar cuenta de las representaciones que de este aspecto movilizan los docentes cuando asignan estas actividades a sus orientados y que, en últimas, determinan la acción educativa de estos actores. Teniendo en cuenta que son los docentes los sujetos generadores de este tipo de actividades, se constituyen en el actor elegido para indagar por las representaciones que se convierten en la base y en la justificación de la asignación de las tareas escolares, así como en el proceso que puede desprenderse de dichas actividades.

\section{Metodología}

Desde el punto de vista metodológico, este análisis se fundamentó en los planteamientos de la semántica de los posibles argumentativos (SPA), que se constituyó en la orientación teórica y metodológica para la realización del trabajo en cuestión, en la medida en que ha desarrollado una estrategia metodológica para adelantar el estudio del significado léxico y del sentido discursivo, para lo cual ha establecido un protocolo de investigación que se estructura sobre una base metodológica investigativa mixta.

Desde la perspectiva de la SPA, el análisis semántico corresponde a la construcción del objeto teórico denominado "significado léxico" (Galatanu, $2003,2005,2007)$. Este objeto se elabora a partir de hipótesis externas sobre el sentido de las ocurrencias en la movilización de las entidades léxicas. Para el efecto, en términos metodológicos, de acuerdo con los planteamientos de la SPA, se definieron dos momentos para la ejecución del proyecto:

a. Construcción del significado léxico a partir de corpus lexicográficos. Esta construcción del significado brinda la posibilidad de establecer el núcleo (en adelante $\mathrm{N}$ ), los estereotipos (en adelante $\mathrm{E}$ ), así como los posibles argumentativos (en adelante PA) de la entidad léxica objeto de estudio, teniendo como referente las definiciones que ofrecen los diccionarios. Para ello, se llevó a cabo el análisis de la entidad léxica tarea de acuerdo con lo establecido en diccionarios representativos de la lengua española (DRAE, Diccionario de Uso del Español de María Moliner, Larousse, Norma).

b. Identificación de las ocurrencias relacionadas con la palabra tarea, que tienen lugar en un discurso definido y delimitado, en este caso, la movilización discursiva que de ese término hacen los docentes. En esta etapa se dio cuenta tanto de las representaciones léxicas como de la valoración activada en ellas, así como del cinetismo del significado léxico en el discurso de los docentes.

Ahora bien, para efectos de obtener la información, se recurrió al cuestionario como instrumento, dado que es una herramienta que permite obtener datos a través de una serie de preguntas, sistemáticamente organizadas (Martínez, 2002). Así, el cuestionario se diseñó con el fin de identificar los 
elementos estables del significado léxico — núcleo-, los elementos que constituyen conjuntos abiertos estereotipos - y la orientación axiológica presente en las ocurrencias. ${ }^{2}$

En lo que a la estructura respecta, este instrumento estuvo conformado por cuatro ítems. El primero orientado hacia la identificación de los términos que los docentes relacionan con la entidad léxica tarea escolar, para ello se recurrió a una pregunta abierta de carácter asociativo; dicha pregunta permitió identificar los estereotipos. El segundo le ofrece al encuestado una serie de encadenamientos discursivos (fundados en argumentación externa) para que determine si son posibles o no, en función de sus representaciones y experiencias; en este caso, se empleó una pregunta cerrada excluyente. Por medio del tercer ítem, se les solicitó a los informantes que elaboraran una definición de tarea, con miras a reconstruir el significado léxico y a identificar los elementos estables de este significado, específicamente el núcleo; aquí se utilizó una pregunta abierta. En el último ítem, se le propuso al docente una situación sobre la tarea escolar para que expusiera su acuerdo o desacuerdo al respecto, esto con el propósito de identificar, estudiar y contrastar los estereotipos, así como analizar los valores convocados en la unidad lingüística tarea escolar por parte de los docentes de Bogotá; en este caso también se empleó una pregunta abierta.

\section{Población}

Teniendo en cuenta lo formulado en el planteamiento del problema, el trabajo se orientó hacia el análisis de los valores sociales que los docentes de lenguas de los ciclos 1 al 5 activan en la entidad léxica tarea escolar. Si bien los actores del proceso educativo son, en principio, docentes y estudiantes, el proyecto limitó la población a los docentes dado

2 Los datos recogidos gracias a la aplicación de estas herramientas se trataron mediante el análisis prototípico y categorial que permite establecer las asociaciones libres más cercanas al núcleo (del significado léxico), así como aquellas situadas en la periferia y que dan cuenta de los estereotipos como conjunto abierto y con mayor exposición al cinetismo. Las actividades de normalización y de conteo de ocurrencias se efectuaron con el programa de análisis Lexico 3. que son estos los que generan y emplean la tarea escolar como parte de su práctica pedagógica. Así, la población objeto de este estudio estuvo constituida, por 118 docentes, distribuidos por ciclos: $\mathrm{C} 1,23$; $\mathrm{C} 2$, 24; C3, 27; C4, 21; C5, 23.

En lo que al nivel de formación respecta, se tiene que un docente cuenta con título de técnico, 39 poseen título de pregrado, 48 tienen título de especialización y 30 cuentan con el título de maestría. Por otro lado, 72 docentes trabajan en el campo de la lengua materna y 42 en la enseñanza de lengua extranjera, fundamentalmente, inglés. El promedio de experiencia docente de la muestra seleccionada es de 11,9 años.

\section{Resultados: análisis y discusión}

Para efectos de analizar y presentar los resultados obtenidos, se parte de la diferencia que la SPA establece entre la construcción del significado léxico y la reconstrucción de la representación que los hablantes poseen de este significado. Estos dos procesos están ligados, respectivamente, al uso de los diccionarios representativos de una lengua (materna $o$ extranjera) en la que se desea hacer la investigación, $\mathrm{y}$ a las informaciones que provienen de los sujetos sociales de interés del estudio, que para este caso correspondió, como se ha señalado, a los docentes de lenguas de instituciones educativas de Bogotá.

Teniendo en cuenta lo anterior, a continuación se exponen los resultados obtenidos en cada una de las etapas, de tal forma que se presenta el análisis de tarea, de acuerdo con lo establecido en los diccionarios y en los datos obtenidos de los docentes. En los dos casos, se establece el núcleo, los valores que contiene dicho núcleo, los estereotipos que los informantes asocian a la palabra en cuestión, así como los valores presentes en estas asociaciones, aspecto que, como plantea Galatanu (2009), configuran el significado léxico y se constituyen en los estratos del análisis semántico. 


\section{La expresión tarea escolar en el discurso lexicográfico}

\section{El núcleo}

A partir de las definiciones encontradas en los diccionarios seleccionados ${ }^{3}$ se estableció el siguiente núcleo (N) para tarea (escolar) (Cfr. Castillo, Ruiz y Santiago, 2014):

\section{Tarea (escolar)}

$\mathrm{N}$ : Sustantivo f.

Obra y trabajo obligatorios PLT dificultad PLT esfuerzo SE tiempo limitado PLT resultado. ${ }^{4}$

De acuerdo con esto, en la definición se identifica como primer bloque de significado del núcleo los términos obra y trabajo que pueden presentarse como sinónimos. Sin embargo, la presencia de estos dos elementos en el núcleo pone de manifiesto la diferencia entre obra como producto y trabajo como proceso, acción o actividad.

El otro elemento de este primer bloque lo constituye el carácter de obligatorio, que lleva a entender la tarea como una imposición de un actor sobre otro; esta imposición, a su vez, conlleva dos aspectos: de un lado, la obligación de cumplir y, de otro, la idea de necesidad que se encuentra implícita en la imposición, por lo tanto, en la obligatoriedad. En este sentido, alguien asigna (el docente) algo (la tarea) y otro debe realizar la actividad (el estudiante).

De acuerdo con el n que se ha definido, esta obral trabajo obligatorios se caracterizan por la presencia de la dificultad, elemento del segundo bloque de significado. Ahora, esta condición implica que para alcanzar lo que el profesor impone al estudiante, o al grupo de estudiantes, se requiere de un esfuerzo - tercer bloque de significado- por parte de quien realiza la tarea. Esto, dado que esforzarse significa, de acuerdo con el DUE, "obligarse alguien a sí mismo a hacer algo para lo que se necesita mucha

3 DRAE, Diccionario de Uso del Español (DUe) de María Moliner, Larousse, Norma.

4 En el núcleo de esta entidad léxica se observan cinco bloques de significado vinculados mediante los conectores virtuales PLT (por lo tanto) y SE (sin embargo), los cuales representan relaciones normativas y transgresivas, respectivamente (Carel y Ducrot, 1999 y 2005; Galatanu, 2007). fuerza física o aplicar intensamente la inteligencia, la voluntad o cualquier facultad espiritual". En consecuencia, el estudiante se obliga a cumplir con la tarea en función de la obligación que el docente le ha asignado. En este orden de ideas, esforzar implica forzar, por consiguiente, obligar.

Una obra o un trabajo que constituyen la tarea, en su primer bloque de significado, obedecen a una obligación y suponen un grado de dificultad que, a su vez, conllevan a un esfuerzo y a una restricción en términos temporales - cuarto bloque de significado- ya que deben realizarse en un tiempo limitado, es decir, en un plazo definido e impuesto por el docente. En este orden de ideas, el profesor asigna, al estudiante, algo por ejecutar de manera obligatoria y establece unos límites en términos de tiempo para que este dé cuenta del resultado, quinto bloque de significado. Este resultado proviene de las actividades que el estudiante realiza en un tiempo que, como se ha señalado, es estipulado por el profesor.

\section{Valores del núcleo}

En cuanto a los valores que se encuentran en el $\mathrm{N}$ de tarea escolar, a la luz de las definiciones de los diccionarios, se puede establecer lo siguiente (tabla 1):

Tabla 1. Valores del núcleo de tarea escolar

\begin{tabular}{|c|c|}
\hline VALOR & N. \\
\hline Pragmático +, deóntico & 3 \\
\hline Alético, epistémico, intelectual +, hedónico-afectivo+/- & 2 \\
\hline Pragmático +/-, intelectual +/-, hedónico-afectivo - & 1 \\
\hline Fuente: Elaboración propia. & \\
\hline
\end{tabular}

Como se puede observar, priman los valores de las zonas axiológica y ontológica (Galatanu, 2003, 2004). En cuanto a la primera, prevalecen los valores pragmáticos positivos, lo cual es coherente con el hecho de que de la realización del trabajo o de la obra se espera un producto (resultado) que debe ser útil para algo y, especialmente, para alguien. Con respecto a los valores deónticos, estos se asocian con el carácter obligatorio (Galatanu, 2003a) que supone la tarea escolar, lo cual forma parte del contrato social que se establece en un aula de clase, de 
las reglas de juego que caracterizan las relaciones en la escuela y que forman parte del currículo.

Los valores aléticos revelan la necesidad de los trabajos impuestos al estudiante y esto para alcanzar los resultados que el docente espera. Es imprescindible precisar que estas actividades propias de las tareas son necesarias porque son útiles, de ahí que sea el grado de utilidad el que determina su necesidad y su obligatoriedad.

Como el trabajo asignado no es exclusivamente físico, sino especialmente de orden intelectual, cognitivo, se comprende claramente la presencia de los valores epistémicos e intelectuales positivos. Estos están relacionados con el saber, con el conocimiento (Galatanu, 2003a) y con el interés y la pertinencia que tiene la actividad, la cual, en principio, genera atención y gusto en el estudiante. Esto último implica la presencia de valores hedónico-afectivos ambivalentes, en la medida en que la tarea conlleva, como se señaló, un grado de dificultad, aspecto que genera posiblemente una afectación en el interés del estudiante. Como esta dificultad exige esfuerzo se hace evidente la presencia de valores hedónico-afectivos negativos, contenidos en la idea de esfuerzo. El carácter negativo de estos últimos valores da cuenta de la fatiga o el cansancio que supone el esfuerzo que el estudiante debe realizar para superar las dificultades propias de la actividad impuesta.

La presencia de valores axiológicos, pragmáticos e intelectuales, ambivalentes, tiene que ver con la posibilidad de que, en algunos casos, la actividad o su objeto represente poca utilidad e interés o un grado de dificultad elevado. En otros casos, esa actividad puede generar interés y motivación para su realización.

\section{Los estereotipos}

Del discurso lexicográfico se obtiene una serie de asociaciones que están relacionadas con los elementos del núcleo de la entidad léxica tarea escolar. En la tabla 2 se presentan los estereotipos y los valores que se les asocian.

Tabla 2. Estereotipos y valores asociados al de tarea escolar
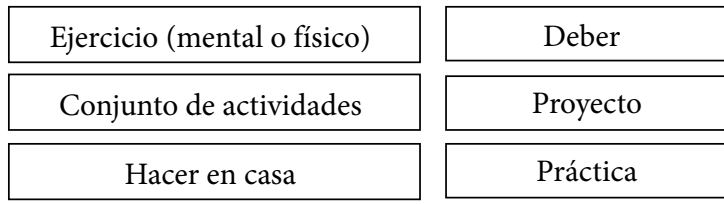
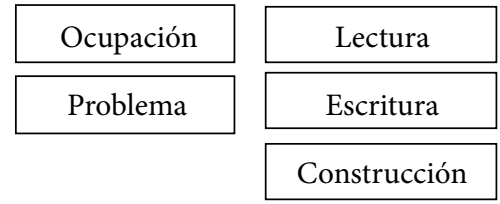

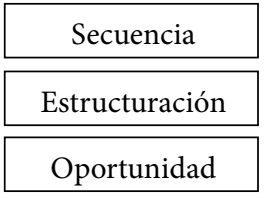

Fuente: Elaboración propia.

De acuerdo con la tabla 2, el ejercicio - tanto mental como físico- está estrechamente relacionado con ocupación, práctica y conjunto de actividades, elementos que refuerzan el primer bloque de significado del núcleo (obra y trabajo). El conjunto de actividades que actualizan el trabajo que supone la tarea se caracteriza por una naturaleza particular que implican una secuencia y una estructuración. Estas entidades léxicas, que remiten a acciones que debe adelantar el estudiante, toman forma más precisa en los términos lectura y escritura. Un amplio número de actividades, en especial las de orden académico, integran la lectura y la producción de textos escritos para su rea- lización. En algunos casos, la tarea se constituye en un problema que el estudiante debe resolver o en un proyecto que debe realizar, lo cual introduce un grado de dificultad mayor; en este contexto, la lectura y la escritura alcanzan mayor exigencia. La lectura y la escritura, como elementos esenciales de la formación del individuo, son pilares en la realización de las actividades estructuradas y secuenciadas en forma de proyectos o de procesos para solucionar problemas. En este orden de ideas, lo que hace el estudiante, en el marco de la tarea, le va a permitir la construcción de diversos elementos del conocimiento, de su aprendizaje, así como de su ser pensante, individual y social. 
Con respecto al término deber, la presencia de este consolida el carácter obligatorio presente en el núcleo; de igual forma, hacer en casa plantea el hecho de que la actividad, el ejercicio - la práctica, el trabajo o la obra obligatorios-, se debe llevar a cabo, en principio, en un contexto particular distinto al salón de clase, en esta medida, la tarea se trata de una actividad de carácter extraescolar que se ejecuta fuera del salón de clase y en un tiempo delimitado, distinto al establecido para el proceso formativo que se adelanta en la institución educativa.

La realización de la actividad en la casa se constituye en un aspecto oportuno, conveniente para el estudiante. El término oportunidad da cuenta, entonces, del carácter adecuado de las acciones para el estudiante. La tarea es una oportunidad que se brinda al estudiante para propiciar y potenciar su proceso de formación y cualificar su aprendizaje.

\section{Los valores en los estereotipos}

El estudio de los valores contenidos en los estereotipos se sintetiza en la tabla 3 .

Tabla 3. Valores asociados a los estereotipos

\begin{tabular}{|l|c|}
\hline \multicolumn{1}{|c|}{ VALOR } & $\mathbf{N .}^{\circ}$ \\
\hline Pragmático & 13 \\
\hline Epistémico & 12 \\
\hline Deóntico, intelectual +, hedónico - afectivo +/- & 6 \\
\hline Alético & 3 \\
\hline Intelectual +/-, hedónico - afectivo + & 1 \\
\hline
\end{tabular}

Fuente: Elaboración propia.

De acuerdo con la tabla 3, los valores pragmáticos positivos y epistémicos aparecen como los más marcados y, al reforzar los mismos valores presentes en el núcleo, se da cuenta de la utilidad que tienen la asignación y la realización de las tareas; es decir, todo lo que implica la tarea (actividad, ejercicio, práctica, actividades) es útil en la medida en que permite o posibilita el aprendizaje del estudiante. De esto dan cuenta los valores de juicio de verdad y axiológicos positivos que predominan en este estrato del significado léxico de la tarea escolar.

Los valores intelectuales positivos presentes en los términos lectura, escritura, problemas y proyectos, entre otros, dan cuenta de la búsqueda del interés de los estudiantes. Desde la perspectiva del profesor, la actividad asignada puede ser valiosa e interesante $y$, entonces, suscitar el interés, el entusiasmo y el bienestar del estudiante; pero a los ojos de este último la acción que se debe realizar, sobre todo por su carácter de obligatoria, no necesariamente es agradable, de ahí la presencia en los estereotipos de los valores hedónico-afectivos ambivalentes.

Para efectos de lograr el resultado previsto en la tarea escolar, se hace necesario que el estudiante realice los ejercicios y actividades asignados para su ejecución fuera del aula. En estos términos se concretan los valores de la zona modal ontológica (aléticos). En todo caso, prima la obligatoriedad sobre la necesidad en este conjunto de asociaciones de tarea escolar. No obstante, es preciso resaltar que el carácter obligatorio de las actividades, representado por los valores ontológicos, es menos enfático en los estereotipos que en el núcleo, lo cual debilita en cierta medida la orientación axiológica de algunos de los elementos estables

\section{La tarea escolar en el discurso de los docentes}

\section{El núcleo}

Para efectos de identificar la noción que tienen los docentes, se recurrió - como se anotó líneas atrása la pregunta tres del cuestionario, en la que se les solicitaba que ofrecieran una definición de tarea escolar. El análisis de estas definiciones permitió establecer que, desde el punto de vista formal, los docentes emitieron, en términos generales, construcciones de carácter atributivo con la estructura: sujeto, enlace, atributo, adyacente, como se puede ver en estos casos (tabla 4). 
Tabla 4. Estructura de las definiciones de los docentes

\begin{tabular}{|l|l|l|l|} 
Sujeto & E & \multicolumn{1}{c|}{ Atributo } & \multicolumn{1}{c}{ Adyacente } \\
\hline Tarea & es & la oportunidad & que tiene el estudiante de reforzar los temas trabajados en el aula \\
\hline Tarea & es & la actividad & que le permite al individuo reforzar un concepto previo \\
\hline Tarea & es & ejercicio & de aplicación de lo visto, explicado y practicado en clase \\
\hline Tarea & es & trabajo & que se desarrolla después de una clase
\end{tabular}

Fuente: Elaboración propia.

Se tiene, entonces, construcciones con predicación nominal, atributo, con el cual se caracteriza o califica el sujeto, tarea. Con respecto al adyacente, este se presenta como complemento especificativo del atributo, es decir, por medio de él se restringe o delimita el significado de aquel, de ahí que se puedan considerar como construcciones restrictivas. Estas especificaciones pueden presentar como nexo el pronombre relativo (que) o preposiciones (de, para, con); en otros casos se utilizan adjetivos (tarea es la oportunidad complementaria de un tema que se está estudiando). En estas estructuras, en consecuencia, el adyacente se convierte, a su vez, en atributo especificativo del atributo, lo cual lleva a que se tengan enunciados atributivos complejos, en los que se inserta un elemento, el adyacente, para expandir un elemento, el atributo.

Con respecto a los atributos, se identificaron 40 formas léxicas. Así, del total de definiciones que ofre- cieron los docentes (150) el atributo que más porcentaje presenta es el de actividad (36,7\%), seguido de oportunidad (10\%), ejercicio (8,7\%), refuerzo $(6,7 \%)$, compromiso (4\%), herramienta $(4 \%)$, estrategia (3,3\%), trabajo (3,3\%) y posibilidad (2,7\%). Estas entidades lingüísticas dan cuenta de los primeros bloques de significado constitutivos de los elementos centrales de la tarea escolar, a partir de los datos que ofrecen los docentes encuestados. De otro lado, a estos términos se les asocian, como adyacentes o complementos, con valor de finalidad, las siguientes unidades léxicas: reforzar, practicar, mejorar, ampliar, profundizar, repasar, complementar, generar, realizar, asignar, obtener, indagar, utilizar, aprender, aclarar. Estos, a su vez, tienen como objetos: tema visto, conocimiento, aprendizajes y conceptos vistos. Lo anterior se puede esquematizar de esta forma (figura 1):

Figura 1. Elementos del núcleo de tarea escolar en las definiciones de los docentes

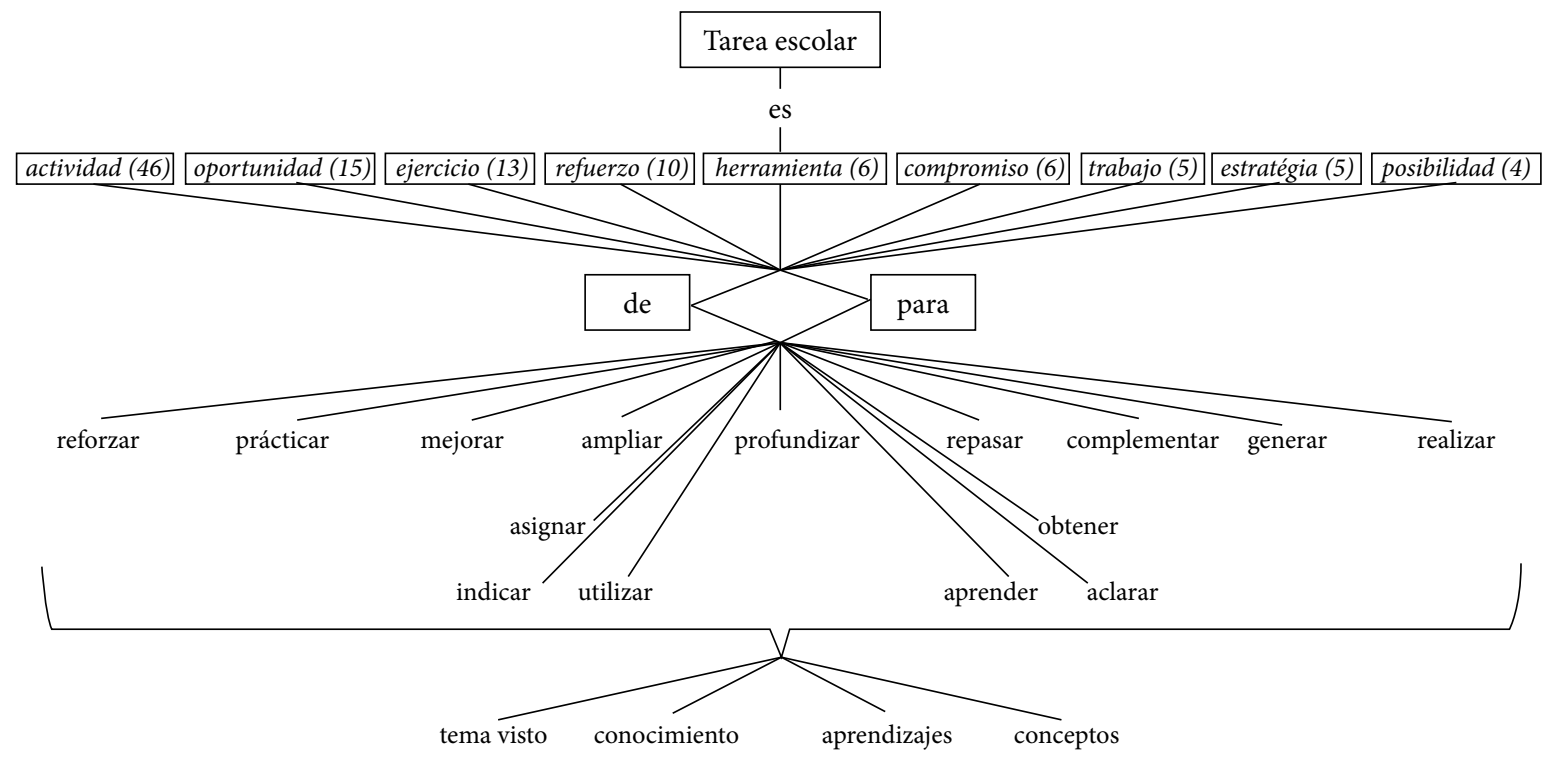

Fuente: Elaboración propia. 
Lo anterior posibilita la reconstrucción del $\mathrm{N}$ de tarea, así:

\section{Tarea (escolar)}

N: Sustantivo f.

Actividad y ejercicio en casa PLT oportunidad de refuerzo PLT practicar PLT ampliar/profundizar temas y conocimientos vistos PLT reforzar y mejorar.

Los docentes encuestados definen la tarea escolar como una actividad y un ejercicio que se realizan en la casa (del estudiante). Actividad remite a una acción o a un conjunto de acciones, específicamente de carácter humano, que se llevan a cabo en un campo determinado. A su vez, ejercicio se refiere a "cada trabajo que se hace para el aprendizaje de cierta cosa” (DUE). En el primer término del bloque de significado, actividad, se destaca la acción misma, mientras en la palabra ejercicio, se precisa que la acción tiene un fin específico: el aprendizaje.

Los docentes señalan que la realización de la actividad y/o el ejercicio se desarrolla en un espacio determinado: la casa. Al enunciar este espacio, se destaca la relación entre el lugar, la vivienda, y sus habitantes, la familia. Esto supone no solamente una relación espacial sino que remite al acompañamiento de los padres, o de otros familiares, en la ejecución de estas actividades.

La actividad y/o el ejercicio son planteados por los docentes como una oportunidad de refuerzo. El carácter oportuno de estas acciones se refiere a que aquello que el profesor asigna "produce buen efecto" $\mathrm{y}$ es "adecuado o conveniente" para el individuo que las lleva a cabo. Asimismo, esa oportunidad da cuenta de que se favorece el refuerzo de algo, lo cual corresponde, en general, a una temática "vista" en clase. El refuerzo corresponde al hecho de "hacer más fuerte cierta cosa" y reforzar remite a "aumentar cierta cosa para hacerla más fuerte o más eficaz" (DUE). Con la inclusión de los términos oportunidad y refuerzo, como elementos del núcleo de tarea escolar, los docentes destacan dos aspectos: en relación con oportunidad, señalan que la actividad o el ejercicio tienen un resultado positivo y benefician al estudiante; en cuanto a refuerzo, los informantes sugieren que la actividad establecida para desarrollar posteriormente tiene como objeto un aspecto que ya se ha tratado en las clases. Al volver sobre lo estudiado en la institución escolar, se espera que el sujeto que desarrolla la acción consolide los contenidos (conocimientos) "vistos" en clase. Esta concepción pone de manifiesto la idea de que el proceso didáctico se fundamenta en la asistencia de los estudiantes a la institución escolar para hacer acto de presencia y regresan a sus casas a estudiar, asimismo, en que el aprendizaje se reduce "a una simple recepción de información en clase, que basta con 'repasar' después en casa" (Meirieu, 2005, p. 19).

Varios aspectos sobresalen en el bloque de significado hecho de practicar a partir de las respuestas de los docentes: el carácter habitual, la continuidad, la repetición, de un lado, y el desarrollo de destrezas, de otra parte. Según las respuestas, este refuerzo, como consolidación de lo estudiado - con antelación-, es alcanzable en la medida en que las acciones del estudiante se realicen de manera habitual y se repitan o ejecuten insistentemente hasta adquirir práctica o destreza. Entonces, si la actividad o ejercicio es una oportunidad de refuerzo implica ampliar y profundizar, lo que equivale a decir que, en el primer caso, prima la idea de extensión, de aumento de la cantidad de elementos constitutivos de los contenidos por reforzar, mientras que, en el segundo caso, se determina la posibilidad de ahondar en esos conocimientos, esto es, "estudiar o examinar seriamente" (DUE) los temas y conocimientos tratados previamente.

El tomar la oportunidad de refuerzo y concretarla mediante una práctica constante con miras a ampliar y profundizar los conocimientos y los temas explicados por el profesor, "vistos" en clase, permite hacer eficaz la serie de actividades realizadas y, entonces, alcanzar el refuerzo, por tanto, el mejoramiento. En lo anterior se puede dar cuenta del último bloque de significado del núcleo correspondiente a tarea escolar y que se enuncia como hecho de reforzar y mejorar. En este orden de ideas, según las definiciones de los profesores, se puede inferir que el mejoramiento como resultado del refuerzo tiene que ver con los conocimientos declarativos y no con un saber-hacer, un desempeño, una destreza 
o las mismas estrategias de aprendizaje, el aprendizaje como actividad cognitiva que contribuye a la transformación del sujeto.

\section{Los valores del Núcleo}

En las definiciones que ofrecen los docentes, y por ende en el $\mathrm{N}$ que resulta de las respuestas, sobresalen valores de las zonas modales de juicio de verdad -epistémico (10)- y axiológica -pragmático positivo (9), intelectual positivo (6), hedónico-afectivo positivo (6)-; y en menor medida los deónticos (2), los aléticos (2) y los hedónico-afectivos ambivalentes (1).

En lo que respecta a los valores epistémicos, estos dan cuenta de lo importante que resulta para los docentes el enfocar las actividades que asignan a sus estudiantes sobre los contenidos, esto es, sobre "temas y conocimientos vistos" en períodos de clase. Como se expuso antes, estos objetos de las actividades y ejercicios se centran específicamente sobre contenidos de orden declarativo. Esto apunta a que en las acciones que concretan las tareas los profesores buscan que los estudiantes continúen en la construcción de una representación del mundo que el profesor ya inició en clase.

En cuanto a la orientación positiva de la zona axiológica, prevalecen los valores pragmáticos, dada la utilidad que las actividades y ejercicios establecidos representan para los docentes y que estos esperan que también lo sean para los estudiantes. Asimismo, los profesores consideran que la actividad, el ejercicio, el hecho de practicar, reforzar, ampliar, profundizar y mejorar son importantes y asignan, dichos elementos, un valor agregado al trabajo desarrollado en clase. Algo es interesante en la medida en que es importante y tiene un valor, por esta razón aparecen como relevantes los valores intelectuales positivos (seis formas léxicas con estos valores asociados a términos del $\mathrm{N}$ ). En principio, este número de valores revela que la actividad que concreta la tarea es interesante para el docente.

El último valor con una presencia importante en los elementos del $\mathrm{N}$, a la luz de los docentes, corresponde a los hedónico-afectivos y esto parece estar determinado por las entidades léxicas oportunidad (de refuerzo), hecho de ampliar, de profundizar y de mejorar. Se trata en este caso de valores positivos contenidos en el buen efecto que supone la oportunidad $y$ en el bienestar generado por el mejoramiento que resulta del refuerzo. Ahora bien, es preciso establecer que para los docentes encuestados esta transformación positiva se funda sobre la consolidación, como se ha señalado, de saberes declarativos.

Frente a la primacía de valores epistémicos y pragmáticos resulta insuficiente el número de valores de la zona modal ontológica: deónticos y aléticos. Si tanto en las actividades y ejercicios como en los contenidos se movilizan valores ligados al saber, al conocimiento, a la búsqueda de claridades y si estos se presentan como útiles para los sujetos, debería identificarse una cantidad superior de valores que dan cuenta de la necesidad y de la obligatoriedad. Lo anterior se fundamenta en la cadena argumentativa saber/conocimiento/certeza PLT utilidad PLT necesidad y obligación; pero se puede encontrar esencialmente el encadenamiento saber/conocimiento/ certeza PLT utilidad SE no necesidad ni obligación.

\section{Los estereotipos}

La identificación de los estereotipos en el discurso de los docentes surge del análisis de la pregunta 1 del cuestionario; por medio de esta, se les solicitaba a los docentes que escribieran las formas léxicas que asocian con tarea escolar. Con respecto a estos estereotipos, se establecieron 441 unidades léxicas. De estas, las que presentan la mayor frecuencia son los 23 expuestos a continuación (tabla 5): 
Universidad Pedagógica Nacional

Facultad de Humanidades

Tabla 5. Entidades léxicas asociadas a tarea escolar

\begin{tabular}{|l|l|l|l|l|l|}
\hline $\mathbf{N}^{\circ}$ oc. & Términos & $\mathbf{N}^{\circ}$ oc. & \multicolumn{1}{|c|}{ Términos } & $\mathbf{N}^{\circ}$ oc. & \multicolumn{1}{|c|}{ Términos } \\
\hline 60 & refuerzo & 35 & aprendizaje & 20 & autonomía \\
\hline 59 & trabajo & 33 & consulta & 19 & esfuerzo \\
\hline 51 & ejercicio & 31 & compromiso & 18 & labor, retroalimentación \\
\hline 49 & actividad & 27 & prática, investigación & 16 & $\begin{array}{l}\text { dedicación, obligación, asignación, oportunidad, } \\
\text { conocimiento }\end{array}$ \\
\hline 41 & responsabilidad & 24 & repaso & 15 & deber, afianzamiento, mejoramiento \\
\hline
\end{tabular}

Fuente: Elaboración propia.

Al establecer la relación de los bloques de significado del núcleo con los estereotipos, se puede dar cuenta de lo siguiente (tabla 6):

Tabla 6. Relación núcleo y estereotipos de tarea escolar

Actividad y ejercicio en casa

PLT

Oportunidad de refuerzo

PLT

Practicar

PLT

Ampliar y profundizar temas y conocimientos vistos

PLT

Reforzar y mejorar
PLT asignación, labor, obligación, deber, esfuerzo, actividad, ejercicio, responsabilidad, compromiso

PLT oportunidad, repaso, refuerzo...

PLt trabajo, dedicación, autonomía...

PLT consulta, investigación, retroalimentación, conocimiento, prática

PLT afianzamiento, mejoramiento, aprendizaje...

Fuente: Elaboración propia.

A partir de la reconstrucción del núcleo, en los datos de los docentes, y de los estereotipos que estos informantes asocian a la entidad lingüística tarea escolar, la SPA propone establecer una serie de PA (Galatanu, 2007; Galatanu y Nikolenko, 2009). Estos PA se generan sobre la base de una asociación de la entidad léxica (tarea) con elementos de sus estereotipos (oportunidad, por ejemplo) y corresponden a secuencias discursivas que podrían aparecer en emisiones discursivas. ${ }^{5}$

5 Estas asociaciones virtuales se estructuran en función de dos haces orientados hacia el polo axiológico positivo o hacia el negativo (Galatanu, 2007, 2006a). Después, el entorno semántico o el contexto contaminan discursivamente estas asociaciones y actualizan la orientación positiva o negativa de los haces de asociaciones.
$\mathrm{Al}$ reubicar los estereotipos identificados entre los docentes encuestados se obtiene la siguiente distribución en el eje axiológico en donde los que tienen mayor tendencia positiva son mejoramiento, refuerzo, aprendizaje y los más negativos corresponden a trabajo, labor y esfuerzo: mejoramiento, aprendizaje, refuerzo, retroalimentación, afianzamiento, oportunidad, autonomía, compromiso, responsabilidad, dedicación, conocimiento, deber, repaso, práctica, investigación, consulta, ejercicio, actividad, asignación, obligación, trabajo, labor, esfuerzo.

Estos PA de tarea escolar, con sus estereotipos, permiten establecer que las representaciones más frecuentes de los docentes y, por ende, las de probablemente mayor presencia e implicación en sus acciones pedagógicas cotidianas, corresponden a 
esta gama amplia de términos que se organizan en torno a los polos axiológicos negativo y positivo.

En el conjunto de estereotipos de la entidad lingüística tarea escolar, identificados en las respuestas de los docentes, aparece un número alto y diverso de asociaciones. Un grupo de estereotipos gira en torno a la idea de acción que caracteriza la tarea escolar. En este orden de ideas, los términos trabajo, ejercicio, labor, actividad, práctica retoman y consolidan el primer bloque de significado de la tarea escolar, a saber, actividad y ejercicio en casa.

La presencia, entre los estereotipos, de consulta e investigación debilitan el cuarto bloque de significado del $\mathrm{N}$ de la tarea escolar, es decir, el hecho de ampliar y profundizar temas y conocimientos vistos. La consulta podría contribuir a lograr que los estudiantes amplíen y profundicen temáticas abordadas en clase, pero resulta en una suerte de contradicción si se tiene en cuenta que refuerzo, repaso, afianzamiento, mejoramiento apuntan a consolidar lo que los sujetos han "visto" en las clases. Además, el estereotipo refuerzo, que aparece como oportunidad y como resultado en el $\mathrm{N}$, es el más frecuente, es decir, se erige como el de mayor asociación con tarea escolar entre las representaciones de los docentes. En este sentido, la búsqueda de refuerzo de algo "visto" contrasta con la consulta y sobre todo con investigación. Esta última dista mucho de lo que en el campo educativo se concibe - y se realizacomo tal, incluso de la definición propuesta por el DUE "estudiar o trabajar en un campo del saber para aumentar los conocimientos sobre una determinada materia”. En todo caso, según los encuestados, las actividades y los ejercicios que asignan los profesores se evidencian fundamentalmente en los estereotipos consulta e investigación.

Para que los estudiantes ejecuten esta serie de acciones, a la luz de estos estereotipos, es preciso que el docente establezca lo que deben hacer. Según estos estereotipos, la tarea no se funda en la voluntad del sujeto que aprende sino en la obligación que emana del profesor; esto se actualiza en los estereotipos asignación, deber y obligación. Se advierte un contraste alto entre estos estereotipos y el $\mathrm{N}$ de tarea escolar debido a la ausencia, en este último, de estos términos que remiten a la obligatoriedad, a los valores deónticos.

Asimismo, la aparición de la palabra esfuerzo, en las asociaciones libres que hacen los docentes, imprime una nueva idea a la realización de la actividad y señala aspectos tales como: fatiga o sufrimiento, subrayando así valores negativos en su ejecución. De otra parte, se incluye al sujeto que realiza la acción puesto que es él quien padece de dicha fatiga y es quien lleva a cabo el esfuerzo. Aunque no aparezca la palabra esfuerzo en el $\mathrm{N}$ de tarea escolar, los términos actividad y ejercicio - cercanos a trabajo- suponen la realización de un esfuerzo y, a su vez, el esfuerzo es constitutivo de la realización de un trabajo.

El esfuerzo que implica la realización de la actividad impuesta por el profesor lleva al estudiante a asegurar dedicación, compromiso y responsabilidad para alcanzar lo que se espera de él. Estos cuatro términos resultan cercanos de la oportunidad, existente tanto en el $\mathrm{N}$ como en los E de tarea escolar, y solamente su transformación en acciones reales permitirá que el sujeto que aprende valore y tome la oportunidad que le brinda el docente para lograr el refuerzo, el repaso, el afianzamiento y el mejoramiento. Entonces, la oportunidad, como estereotipo, consolida la idea de oportunidad de refuerzo, presente en el $\mathrm{N}, \mathrm{y}$, de alguna manera, solapa la imposición y la obligatoriedad que provienen del docente.

Tres estereotipos completan las asociaciones con la tarea: aprendizaje, conocimiento y autonomía, pero carecen de una verdadera articulación, entre ellas y con el $\mathrm{N}$ de tarea escolar. Aunque el término conocimiento que da cuenta de la "presencia en la mente de ideas acerca de una cosa", de la "representación de las cosas o de cierta cosa" refuerza el cuarto bloque de significado del $\mathrm{N}$, el aprendizaje se limita al almacenamiento de contenidos que versan sobre temas diferentes que el profesor ha tratado. Así, si el aprendizaje se enfoca en conocimientos y deja de lado destrezas y desempeños, por ejemplo, resulta una asociación que refuerza elementos del $\mathrm{N}$, pero que no enriquece la concepción de aprendizaje ni, 
por ende, la de tarea escolar. Entonces, si el aprendizaje, logrado con el refuerzo - este último como la asociación más recurrente en los estereotipos de tarea-, es la meta de las tareas, es insuficiente este fin y no cumple con otras exigencias.

En cuanto a la autonomía, esta asociación tarea PLT autonomía no parece evidente, pero a juzgar por todos los elementos del $\mathrm{N}$ se podría comprender que en la medida en que no existe, en el bloque de significado, algún elemento que anule la idea de autonomía, se puede tomar como posible. En esta dirección, es admisible proponer la siguiente asociación, en una argumentación externa: tarea PLT actividad/ejercicio en casa PLT oportunidad de refuerzo PLT hecho de practicar PLT hecho de ampliar $y$ profundizar conocimientos y temas vistos PLT hecho de reforzar/mejorar PLT autonomía. Sin embargo, la coexistencia de autonomía con otros estereotipos debilita esta asociación. Lo anterior porque palabras como asignación, deber, obligación no revelan una orientación hacia la autonomía, la decisión del sujeto que aprende, su voluntad, sino que, por el contrario, sugieren una menor actividad volitiva de este individuo y una preponderancia del docente. En consecuencia, se denota una ambigüedad o, mejor, una ambivalencia entre algunos de los estereotipos que los docentes asocian con la tarea escolar.

\section{Los valores en los estereotipos del discurso de los docentes}

En los datos que ofrecen los docentes se pueden identificar los siguientes valores activados en los estereotipos (tabla 7):

Tabla 7. Valores en los estereotipos de tarea escolar

\begin{tabular}{|c|c|}
\hline Valor & $\mathbf{N}^{\circ}$. \\
\hline Pragmático + & 16 \\
\hline Epitémico & 14 \\
\hline Deóntico & 12 \\
\hline Intelectual + & 11 \\
\hline Alético & 7 \\
\hline Hedónico - afectivo + & 5 \\
\hline Ético - moral +, volitivo & 3 \\
\hline Pragmático +/-, intelectual +/-, hedónico - afectivo - & 1 \\
\hline
\end{tabular}

Fuente: Elaboración propia.
Al estudiar la inscripción de valores en los estereotipos de la tarea escolar, se advierte la superioridad de la zona modal axiológica en la que se cuentan 38 apariciones de dichos valores (tabla 7). Esto pone de manifiesto la importancia de valores sociales complejos presentes en las concepciones que de la tarea tienen los encuestados. También es marcada la zona modal ontológica (19 activaciones), lo cual revela que las representaciones de los encuestados están asociadas a la idea sobre la existencia del mundo natural y social y que la tarea se relaciona con la obligación y la necesidad. Ahora bien, lo obligatorio y lo necesario de la tarea se centran en otros valores, contenidos estos en la zona modal de juicio de verdad, específicamente, los epistémicos. El número importante de estos valores presentes en los estereotipos (14) lleva a generar la hipótesis de que el interés en contribuir a una representación del mundo entre los estudiantes, por parte de los docentes, se limita a pretender alcanzar saberes declarativos, lo que deja de lado - como se mostró antes - otros componentes del aprendizaje y de la formación de los nuevos ciudadanos.

Si se detallan los valores de la zona axiológica, se advierte que los de mayor presencia corresponden a los pragmáticos positivos. El alto número de estos valores sugiere que los encuestados movilizan en sus representaciones el sentido de la utilidad de la tarea y de las actividades que la actualizan y concretan. En esta vía, la tarea escolar aparece entre los docentes como utilidad, y esto, en principio, porque apunta a repasar, reforzar, retomar lo que se ha visto en clase. Sin embargo, esto no se revela suficiente como asociaciones ni como realidades, ni como idea de acciones efectivas, de lo que la tarea es para el conjunto de encuestados. Los valores pragmáticos positivos se inscriben en los estereotipos refuerzo, trabajo, ejercicio, actividad, aprendizaje, consulta, práctica, investigación, repaso, autonomía, labor, retroalimentación, oportunidad, afianzamiento y mejoramiento. Estos términos denotan tanto las actividades que permiten concretar las tareas y el propósito de estas como el carácter mismo de la tarea, esto es: oportunidad. 
Lo expuesto en el párrafo anterior se consolida con la presencia de valores epistémicos, de la zona modal de juicio de verdad, en la medida en que lo que es objeto de ampliación y profundización con miras a alcanzar un refuerzo corresponde a una serie de conocimientos que, actualizados en temáticas, el profesor habría explicado en clase.

A los valores pragmáticos positivos y epistémicos se agregan los correspondientes a la zona modal ontológica, en especial, los deónticos. Estos últimos activan entre los estereotipos la obligación de cumplir con la asignación de las actividades por parte del docente. La tarea escolar no solo conlleva la imposición por parte del maestro sino que, a su vez, la actividad o el ejercicio se convierten en sí mismos en obligatorios y esto implica unos condicionamientos en términos de tiempo y de ejecución. Las prácticas cotidianas en las instituciones educativas, en el contexto nacional, permiten comprobar esta orientación que ha tomado la tarea escolar en el sentido de que se debe ordenar la realización de tareas y esto se ha transformado en una exigencia y en un hábito que en muchas ocasiones no toma en cuenta los verdaderos objetivos de estas actividades. La tarea se ha convertido, entonces, en una regla social, específicamente escolar, en una acción inherente al acto educativo para la cual no se tiene en consideración el tiempo que requiere. Esta transformación de la tarea en una especie de acto reflejo desdibuja los reales propósitos (metas, fines, objetivos, desarrollo de estrategias, destrezas, desempeños, etc.) que debería tener la tarea en una educación diferente y en interacciones centradas en las propuestas y acuerdos de los actores educativos. En este mismo orden de ideas, la complejidad de la tarea impuesta supera el tiempo necesario para llevarla a cabo. El número limitado de ocurrencias del estereotipo tiempo en las respuestas de los docentes confirma los aspectos anteriormente expuestos. El escaso número de asociaciones de tarea escolar con elementos relacionados con los instrumentos, los medios y las maneras necesarias para llevar a cabo las actividades asignadas refuerza la idea de la tarea como hábito-obligación sin contemplar todos los factores que involucra la realización de dicha actividad.
En la zona modal axiológica resalta también el número de valores intelectuales positivos que se inscriben en términos como refuerzo, trabajo, ejercicio, actividad, aprendizaje, consulta, práctica, investigación, labor, afianzamiento y mejoramiento. Para los docentes encuestados resulta una experiencia positiva, interesante, la tarea escolar dado que, según sus asociaciones, contribuye a alcanzar aquello a lo que hacen referencia los términos que relacionan con esta actividad académica. En un gran número de estas palabras asociadas a la tarea se inscriben valores pragmáticos positivos e intelectuales positivos, esto lleva a establecer que la utilidad conduce a encontrarla como interesante, lo que se puede sintetizar en: tarea escolar PLT útil PLT interesante.

Como ya se ha expuesto, los estereotipos entre los encuestados revelan la obligatoriedad de la tarea, a tal punto de convertirse en obligación per se, y en ellos se inscriben, por lo tanto, los valores deónticos. En la misma zona modal se encuentran los valores aléticos, pero su inscripción en las asociaciones de los profesores no es muy importante, lo que lleva a determinar que la tarea tiene una limitada relación con necesidad. Contrasta la primacía de la obligatoriedad en los términos asociados a las tareas escolares con el bajo número de palabras que remiten a los valores aléticos, dado que lo necesario alude a lo primordial, lo indispensable, lo fundamental y lo esencial para que algo exista, se desarrolle o simplemente se dé. Por lo tanto, la relación entre lo deóntico y lo alético no es consistente para el caso de la tarea escolar, desde la percepción de los profesores consultados. Esta situación entre la necesidad y la obligación se puede exponer en la siguiente argumentación externa: tarea PLT obligación PLT necesidad, y parecería adecuado encontrar una relación del tipo tarea PLT necesidad PLT obligación o tarea PLT necesidad y obligación.

Frente a lo expuesto sobre los valores deónticos y aléticos, pragmáticos e intelectuales positivos, así como epistémicos, en cuanto a su número e implicaciones para la tarea escolar, se debe señalar la escasa cantidad relacionada con los hedónico-afectivos positivos, los ético-morales positivos y los volitivos. De un lado, la débil presencia de lo hedónico-afec- 
tivo se convierte en un efecto del carácter obligatorio de la tarea escolar y corrobora la superioridad de valores deónticos. Se puede establecer, según las respuestas, que las actividades asignadas no generan sentimientos de bienestar, no se proyectan en situaciones agradables para los estudiantes. Esto se relaciona de manera cercana con el bajo número de valores volitivos, especialmente porque se reitera la ausencia de la voluntad de quien cumple con las tareas, esto en el sentido de que no proviene de él la intención ni la decisión de asignar(se) o imponer(se) las actividades que debe desarrollar en casa.

\section{Contrastación discurso lexicográfico y concepciones de los docentes}

\section{El núcleo}

En el marco de las orientaciones metodológicas de la SPA, es preciso comparar la referencia representada por el discurso lexicográfico en lengua española y el objeto de interés de este proyecto, a saber, el resultado de la reconstrucción del significado léxico de tarea escolar a partir de las respuestas de los docentes encuestados (tabla 8).

Tabla 8. Comparación de los núcleos de tarea escolar: discurso lexicográfico y concepciones docentes

\begin{tabular}{|c|c|}
\hline $\begin{array}{c}\text { Núcleo lexicográfico } \\
\text { Obra y trabajo } \\
\text { obligatorios } \\
\text { PLT } \\
\text { Dificultad }\end{array}$ & $\begin{array}{c}\text { Núcleo según } \\
\text { encuestados }\end{array}$ \\
\hline PLT \\
Esfuerzo & Optividad y ejercicio en casa \\
\hline SE & Hecho de practicar \\
\hline Tiempo limitado & PLT \\
\hline PLT & Hecho de ampliar y profundizar \\
\hline Resultado & Hecho de reforzar y mejorar \\
\hline
\end{tabular}

Fuente: Elaboración propia.

Se advierten, en un primer momento, dos grandes diferencias: la ausencia del elemento obligatorio(s) en el núcleo, según las respuestas de los docentes, y la presencia en este último del término (en) casa. Estos dos elementos anuncian que los docentes sitúan las actividades a desarrollar por los estudiantes en su hogar y probablemente con el acompañamiento de sus padres o, quizá, con su ayuda como relevos del profesor. La dimensión espacial no es fundamental en el núcleo lexicográfico, mientras que en las definiciones de los docentes, y por ende en su concepción más arraigada de tarea escolar, las acciones que actualizan la tarea se ejecutan de manera clara y específica en la casa. Por supuesto, esta precisión del espacio en el que ocurre el desarrollo de la tarea tiene implicaciones en el campo de los recursos, los medios, los instrumentos $y$, entre otros, los apoyos por parte de los habitantes de la casa. Se hace necesario preguntarse, ¿qué deben hacer los estudiantes en su casa para cumplir con la tarea asignada?

La ausencia en el núcleo del carácter obligatorio de la tarea escolar demuestra que entre los elementos esenciales de la tarea, a la luz de los encuestados, no se asume la tarea como una obligación sino como una oportunidad (de refuerzo). En este orden de ideas, la oportunidad, entendida como aquello que es adecuado, conveniente y que tiene efectos positivos, se presenta como una ocasión, una actitud, una situación, una propuesta que generaría reacciones positivas y agradables en los sujetos a quienes se les asignan las tareas. Esto contrasta con los comentarios, reacciones y quejas sobre las problemáticas de las tareas, sus excesos y confusiones tanto para los estudiantes como para los padres y acudientes, quienes no siempre están en capacidad de guiar la ejecución de actividades que sobrepasan sus posibilidades y los aprendizajes y capacidades de los niños y los jóvenes. Al respecto, Meirieu señala, como problemática asociada a las tareas, el hecho de que muchas veces.

El trabajo mandado no está adaptado al alumno (es demasiado fácil o demasiado difícil), está insuficientemente explicado, (los enunciados no están claros) o "no tiene sentido" para el alumno; son ejercicios formales de los cuales no se sabe qué es lo que permiten aprender ni qué problemas intelectuales 0 concretos permiten resolver (2005, p. 18).

Según los diccionarios, se tiene una serie de elementos estables que de manera general sí corres- 
ponderían a lo que habitualmente se entiende como tarea en el contexto educativo de esta región del país. Es así como tarea PLT obra y trabajo obligatorios PLT dificultad PLT esfuerzo SE tiempo limitado PLT resultado, según el discurso lexicográfico corresponde con las acciones que habitualmente y de manera general caracterizan a la tarea en las instituciones escolares de Bogotá. A la luz de este núcleo del significado, la tarea escolar comprende productos y acciones que se establecen como obligatorias, entonces, de ejecución imperativa; esta cualidad de lo que el estudiante debe hacer y alcanzar se caracteriza por la dificultad o, al menos, por cierto nivel de dificultad, para lo cual el sujeto que aprende debe asegurar un esfuerzo, con mayor razón porque las acciones amplias por ejecutar y cumplir se deben ejecutar en un tiempo restringido.

Ahora bien, el núcleo no revela la idea del espacio en donde se realizará la tarea, lo cual abre el número de opciones sobre la dimensión espacial, esto es que no solamente se pueden llevar a cabo en casa, sino también en otros ambientes como bibliotecas, museos, en el comercio y en el colegio o la escuela misma, en el salón de clase, por ejemplo. Por último, el resultado, aunque aparece como demasiado puntual, es, en realidad, muy general, pues puede contener diversas realizaciones que conciernen a varios componentes del aprendizaje, que, pese a que se trata de un resultado, correspondería a las dimensiones cognitiva, afectiva, social, a destrezas y habilidades, y no solamente a saberes específicos o a un saber enciclopédico. Es en este último elemento en el que se centra otra diferencia marcada entre el núcleo extraído de los diccionarios y el que se generó a partir de las definiciones de los docentes encuestados. Se trata del objeto de la tarea escolar: algo restringido, como en el significado reconstruido, o quizá más amplio, general, de mayor alcance, como en el significado lexicográfico.

Si se retoma el núcleo del significado reconstruido, se logra advertir que tarea PLT actividad y ejercicio en casa PLT oportunidad de refuerzo PLT hecho de practicar PLT hecho de ampliar y profundizar temas y conocimientos vistos PLT hecho de reforzar y mejorar dan cuenta de que la acción de reforzar y mejorar son la concreción de la ampliación y la profundización de contenidos de un saber, de una temática que se trató en clase o, como manifiestan los encuestados, fue "vista" en clase. En consecuencia, el estudiante refuerza un saber, un tema, un conocimiento gracias a la oportunidad que le ha dado el docente al establecer una actividad o un ejercicio para desarrollar en casa. Para lograr este refuerzo, este mejoramiento, el estudiante debe practicar, pero ¿qué es lo que practica, si el objeto es un tema o un conocimiento tratados en clase?

En conclusión, el núcleo proveniente de las encuestas es más restringido en el primer bloque de significado y, por ende, en las implicaciones de los otros bloques. Sin embargo, se presenta como menos preciso que el que proviene de los diccionarios en el sentido en que carece de la temporalidad y, además, limita de manera marcada la dimensión espacial. Luego, reaparece la cualidad de restringido al limitar los objetos de las tareas escolares a contenidos declarativos. Se puede inferir que lo que el estudiante mejora es el conocimiento de un tema, lo cual parece insuficiente para contribuir a una educación y a una formación más amplia, holística y de mayor alcance.

\section{Los valores inscritos en los núcleos}

El estudio de los elementos del núcleo se refuerza con los valores inscritos en ese estrato del significado léxico de los dos datos analizados: diccionarios y docentes (tabla 9).

Tabla 9. Comparación de los valores

\begin{tabular}{|l|c|c|}
\hline \multicolumn{1}{|c|}{ VALOR } & Diccionarios & Profesores \\
\hline Deóntico & 3 & 2 \\
\hline Pragmático + & 3 & 9 \\
\hline Hedónico-afectivo + & & 6 \\
\hline Alético & 2 & 2 \\
\hline Epistémico & 2 & 10 \\
\hline Intelectual + & 2 & 6 \\
\hline Hedónico-afectivo +/- & 2 & 1 \\
\hline $\begin{array}{l}\text { Pragmático +/-, intelectual } \\
+/-, \text { hedónico-afectivo - }\end{array}$ & 1 & \\
\multicolumn{2}{|c}{ Fuente: Elaboración propia. } \\
\hline
\end{tabular}


De acuerdo con esta tabla, existe una coincidencia en los dos núcleos debido a que prevalecen los valores de la zona modal axiológica, pero se distancian luego en cuanto que entre los docentes se movilizan primordialmente valores de la zona de juicio de verdad, mientras ese lugar es ocupado por la zona modal ontológica en los diccionarios. En lo atinente a los valores modales axiológicos, en el núcleo derivado de las concepciones de los docentes prevalecen los pragmáticos positivos, dada la importancia que le conceden a la tarea escolar y a su utilidad para el refuerzo de contenidos vistos en clase, y estos últimos reflejan los valores epistémicos que se encuentran mucho más representados en el núcleo en la medida que son los más numerosos. Un aspecto llamativo consiste en la activación de valores hedónico-afectivos positivos por parte de los docentes, mientras no aparecen en el núcleo proveniente de los diccionarios. Se advierte, entonces, una coherencia interna en cada núcleo pues la obligatoriedad, la dificultad y el esfuerzo como elementos del núcleo lexicográfico se convierten en desencadenadores de reacciones y de sentimientos no necesariamente positivos, por parte de aquellos que deben desarrollar las tareas; además, los términos en sí mismos remiten a la inscripción de valores negativos. También, es congruente el núcleo generado en las respuestas de los informantes, ya que la oportunidad, la práctica, la profundización y el mejoramiento no hacen más que fortalecer al individuo $y$ sus aprendizajes, lo que genera una sensación agradable, de bienestar e, incluso, alegría. Pese a estas cadenas argumentativas del núcleo de los encuestados, y como se expuso antes, el contexto educativo y las concepciones y, sobre todo, las experiencias de estudiantes, docentes y padres de familia muestran una pobre presencia de valores positivos, especialmente, hedónico-afectivos, en la concepción de tarea escolar.

Otro aspecto revelador, en clara relación con lo expuesto en otros apartados, corresponde a la diferencia de valores epistémicos. Son estos los que se inscriben de manera mayoritaria en el núcleo de las definiciones de los docentes, por lo tanto, dan cuenta de la importancia que los docentes otorgan a los contenidos como el objeto de las tareas escolares, a este afán por completar o cumplir los programas.
Esto se transforma en una búsqueda incansable por agotar todos los temarios seleccionados, acordados o impuestos por los establecimientos escolares. Se hace imprescindible preguntar, nuevamente, ¿cuál es el propósito de estos centros educativos y cuál el de los docentes y sus tareas? Se podría considerar que la tarea se ha transformado y, por supuesto, su concepción y su realización efectiva en las acciones cotidianas. En este orden de ideas, la tarea supliría las funciones de los docentes que, por diversos aspectos, no alcanzan a cumplir lo establecido o lo definido en los programas o en sus clases, de ahí que buscarían contribuir al cumplimiento de esos programas, más que al aprendizaje y el desarrollo integral de los estudiantes.

Frente a estas orientaciones hacia lo epistémico, según el núcleo en el discurso de los profesores, la generalidad de valores es más distribuida -en número- en el núcleo lexicográfico. En esta vía, los valores epistémicos se armonizan con los deónticos, los pragmáticos positivos, los aléticos y los intelectuales positivos, e incluso con los hedónicoafectivos positivos y ambivalentes. Ahora bien, esta ambivalencia es significativa en el núcleo lexicográfico, mientras en el núcleo de los informantes es demasiado limitada para alcanzar relevancia en los valores del núcleo y, por ende, en las implicaciones. Esto permite concluir, de un lado, que para los docentes, entre los elementos estables del significado, la tarea escolar no es obligatoria y es útil, en consecuencia, lo que en su marco se desarrolla o se aprende genera bienestar, esto es, valores positivos. Y, de otro lado, una idea mucho más general de la tarea escolar, planteada en las definiciones de los diccionarios, es que esta ambivalencia en los valores hedónico-afectivos supone que en función de las realizaciones, de los discursos, las experiencias, esta entidad léxica puede orientarse positiva o negativamente, lo cual es coherente con todos los elementos del núcleo. En virtud de los procesos que llevan a cumplir con la obligatoriedad de la obra o del trabajo, lo cual demanda esfuerzo para enfrentar la dificultad, así como de los resultados obtenidos, el sujeto puede sentir tranquilidad por lo ejecutado y logrado o, al contrario, frustración, fatiga y malestar. 


\section{Los estereotipos}

Tabla 10. Comparación de los estereotipos de tarea escolar: discurso lexicográfico y concepciones docentes

\begin{tabular}{|c|c|c|c|c|c|}
\hline \multicolumn{2}{|c|}{ Esterotipos diccionarios } & \multicolumn{4}{|c|}{ Esterotipos encuestas } \\
\hline Ejercicio (mental o físico) & Lectura & Refuerzo & Trabajo & Ejercicio & \\
\hline Hacer en casa & Deber & Responsabilidad & Consulta & Compromiso & Práctica \\
\hline Ocupación & Escritura & Aprendizaje & Repaso & Esfuerzo & Obligación \\
\hline Conjunto de actividades & Secuencia & Investigación & Autonomía & Dedicación & Actividad \\
\hline Proyecto & Práctica & Retroalimentación & Labor & Oportunidad & Asignación \\
\hline Problema & Estructuración & Conocimiento & Deber & Afianzamiento & \\
\hline Construción & Oportunidad & Mejoramiento & & & \\
\hline
\end{tabular}

Fuente: Elaboración propia.

Una primera aproximación a los dos conjuntos de estereotipos (tabla 10) permite encontrar que los docentes asocian un número considerable de términos a tarea escolar que supera al número de palabras referidas a esa entidad lingüística en los diccionarios. Esto da cuenta de la diversidad de representaciones que exponen los docentes sobre la tarea escolar y revela su formación, sus experiencias y sus creencias. Asimismo, se encuentran algunos elementos en común tales como: ejercicio, actividad, práctica, deber y oportunidad. La aparición de estos cinco estereotipos entre los profesores muestra una coincidencia, en su discurso, con los estereotipos identificados en los datos de los diccionarios. Esto quiere decir que se presenta una correspondencia con lo socialmente aceptado en el plano lingüístico, esto es, en lengua española, con el discurso lexicográfico, en cuanto a asociaciones se refiere; lo que no sugiere una relación coherente con las prácticas pedagógicas de los docentes.

Pese a las similitudes expuestas, los estereotipos lexicográficos precisan dos palabras comunes: el ejercicio y las actividades. Los docentes relacionan la entidad tarea escolar como actividad, en general, como la acción, mientras que el discurso lexicográfico la presenta como un conjunto, esto quiere decir que se presume organización y estructuración de esas actividades. En cuanto al ejercicio, los diccionarios especifican que se trata tanto de lo físico como de lo mental, lo que expone una representación más amplia de la tarea, ya sea como un medio para alcanzar un fin o como un fin en sí mismo, mientras las respuestas de los docentes se orientan hacia una noción mucho más global. En este orden de ideas, es posible pensar que en los estereotipos identificados entre los docentes no dan cuenta de elementos que precisen el carácter sistemático y metódico en la planeación, preparación, realización y seguimiento de la tarea. Si no aparecen estas precisiones en las emisiones lingüísticas de los docentes, se puede proponer una hipótesis en dos vías posibles: los docentes las desconocen efectivamente y no están presentes en sus representaciones ni en sus acciones o, quizá, tienen conciencia de estas características pero no las consideran relevantes en su acción docente.

En lo que respecta a deber, práctica y oportuni$d a d$, se puede advertir que en los estereotipos lexicográficos el deber actualiza y refuerza el elemento obligatorio presente en el núcleo. Se hace necesario recordar que en el núcleo derivado de las encuestas la idea de obligatoriedad no está presente explícitamente, pero sí aparece entre las asociaciones de los profesores, lo que lleva a considerar que la oportunidad de refuerzo, como elemento del núcleo, se transforma en deber, esto es: se debilitan los valores presentes en la oportunidad y se introducen los deónticos. De otro lado, se destaca la reiteración de las concepciones oportunidad y practicar/práctica en las respuestas de los informantes, pues aparecen tanto en el núcleo como en los estereotipos identificados. Esto sugiere que la idea de los docentes sobre la tarea escolar se refuerza mediante la inclusión 
de los términos oportunidad (que da el docente) y práctica que resulta de esa oportunidad. Además de la transformación tarea escolar PLT oportunidad PLT deber, la práctica conlleva a continuidad, idea de repetición, hábito y aplicación, lo que puede resultar en destreza. Se hace necesario agregar que los tres primeros elementos de la palabra práctica revelan acciones continuas, repetidas y habituales que no necesariamente apuntan a aprendizajes enmarcados en las concepciones y orientaciones educativas actuales.

En consonancia con lo planteado para los núcleos, se encuentra que hay un mayor número de términos en las asociaciones ofrecidas por las encuestas aunque no incluyen aspectos referidos a elementos tales como construcción, secuencia y estructuración que remiten al proceso y que muestran la realización de la tarea como un conjunto de actividades que necesita de unas etapas o fases, de una organización, de una sistematicidad, de unas orientaciones metodológicas y, por ende, de una programación didáctica. Aunque el número de estereotipos asociados por los encuestados a tarea escolar es elevado (441), solamente el 5,2\% es significativo en razón a su aparición en las respuestas de los docentes, lo cual corresponde a 23 términos, como se expuso.

Se identifican algunas similitudes de los dos conjuntos de asociaciones que tienen que ver con el hecho de hacer algo en un período de tiempo: ocupación, en los diccionarios, y trabajo y labor, entre los docentes. Aunque no se presenta una coincidencia en la aparición del término ocupación en los dos conjuntos, es posible identificar rasgos semánticos comunes entre dicha palabra y trabajo y labor. En este orden de ideas, los encuestados, con sus dos términos, amplían las asociaciones que se encuentran en los diccionarios. Labor se define como la acción de trabajar, mientras que trabajo aparece como la actividad en que alguien se ocupa y ocupación se refiere al trabajo en que alguien se ocupa. El hecho de que los diccionarios recurran a alguno de los tres términos para definir a los otros, reafirma lo expuesto en relación con las similitudes. Entonces, se verifica la correspondencia de los estereotipos entre los encuestados con el protocolo semántico de tarea escolar.

Los estereotipos responsabilidad, autonomía, compromiso y dedicación, entre docentes, centran la acción, la realización, así como el hecho de asumir las implicaciones del desarrollo y del resultado en manos del estudiante. Este último debe ser responsable, autónomo, comprometido y dedicado frente a las actividades que asigna el docente. Los estereotipos que ofrecen los profesores no revelan su participación, como agentes, en el desarrollo de la tarea; tal como se mencionó antes, no proporcionan elementos en términos de su planificación, supervisión ni evaluación. Se hace necesario preguntarse por el papel del docente en cuanto a sus responsabilidades, sus acciones, sus compromisos y sus obligaciones. Estas cuatro asociaciones de los encuestados no están acordes con el protocolo semántico de la tarea escolar, pero amplían los elementos básicos de los estereotipos lexicográficos. Las representaciones que de estas se desprenden no aparecen en el discurso lexicográfico, a tal punto que por su presencia inscriben valores ético-morales positivos e incluso volitivos en los estereotipos lexicográficos.

A diferencia de los estereotipos lexicográficos y de su relación con el núcleo derivado de los diccionarios, la entidad léxica refuerzo, que aparece como la de mayor ocurrencia entre los encuestados, reitera y consolida uno de los elementos del núcleo según las respuestas. Dicho de otra forma, la concepción de la tarea como refuerzo es tan marcada, y está tan anclada en las representaciones y en las acciones de los profesores, que aparece en la definición de la tarea escolar y se consolida, se proyecta, en los estereotipos junto con sus valores complejos y su insistencia en la zona modal epistémica. Entonces, se da aquí otra diferencia interesante entre la idea general representada en los diccionarios de lengua española y en las definiciones y asociaciones que circulan entre los docentes y que, probablemente, se actualizan en sus acciones cotidianas en las instituciones escolares. Se advierte, a manera de reiteración, que la concepción de la tarea entre los 
encuestados es muy restringida en la medida que solamente, o prioritariamente, se orienta hacia el refuerzo y, de manera específica, a la consolidación de saberes declarativos, lo cual se concreta, en los estereotipos, mediante la palabra afianzamiento.

El trabajo y la labor, en las representaciones de los docentes, se materializan, mediante la asignación, en actividades específicas como repaso, consulta e investigación, pero estas dos últimas son demasiado generales en comparación con los estereotipos lexicográficos lectura, escritura, problema y proyecto. Es significativo el hecho de que en el numeroso conjunto de asociaciones de los docentes encuestados y entre las más frecuentes no aparezcan términos que remitan a acciones más precisas y cuyas realizaciones se encuentran en la base de la acción transformadora en los estudiantes, tales como la lectura y la escritura, para el amplio espectro de temáticas que se abordan en las instituciones educativas. Asimismo, las tres palabras en las respuestas de los docentes se deslindan de la idea general de tarea que circula según los diccionarios, y esto para insistir en el refuerzo mediante el repaso, pero para ampliarse y desdibujarse a través de consulta e investigación. En este mismo sentido, para los docentes, la tarea no se construye a través de la lectura y la escritura como prácticas y habilidades comunicativas, ni mediante problemas por resolver ni proyectos por realizar, sino cimentada en el retomar lo desarrollado en el aula, según sus respuestas, pero contradictoria con la consulta y la investigación. Se hace necesario preguntarse ¿qué repasan los estudiantes?, ¿qué consultan? y ¿qué investigan? ¿Acaso se podría estar frente a la tarea como un fin y no como un medio? y ¿qué razones y finalidades la animan?

En relación con lo anterior, y en función de las respuestas de los encuestados, los términos repaso, consulta e investigación apuntan a mejorar el conocimiento que tienen los sujetos que desarrollan las tareas. Se puede también comprender que este proceso de mejoramiento se alcanza gracias a la retroalimentación que provee el docente, lo que lleva, en últimas, al aprendizaje. Se puede asumir que la cadena argumentativa retroalimentación PLT mejoramiento PLT aprendizaje es sólida, y parece serlo efectivamente, pero se debilita con el objeto de estos componentes: el conocimiento. ¿Qué es lo que se mejora a partir de la realimentación que entrega el docente?, ¿y qué se aprende? Al parecer se trata del conocimiento, esto es la reiteración de la zona modal epistémica, que sin ser negativo per se, se vuelve insuficiente frente a la diversidad de posibilidades de desarrollo y de transformación que tienen las tareas escolares. De igual manera, convendría insistir en las preguntas sobre el porqué y el para qué de las tareas, así como en los otros componentes de estas acciones: ¿quién(es)?, ¿cómo?, ¿dónde?, ¿con qué? y ¿cuándo?

\section{Los valores en los estereotipos}

Tabla 11. Los valores inscritos en los estereotipos lexicográficos y en las encuestas

\begin{tabular}{|l|c|c|}
\hline \multicolumn{1}{|c|}{ VALOR } & Diccionarios & Profesores \\
\hline Pragmático + & 13 & 16 \\
\hline Epistémico & 12 & 14 \\
\hline Deóntico & 6 & 12 \\
\hline Intelectual + & 6 & 11 \\
\hline Hedónico-afectivo +/- & 6 & \\
\hline Alético & 3 & 7 \\
\hline Intelectual+/- & 1 & 1 \\
\hline Hedónico-afectivo + & 1 & 5 \\
\hline Ético-moral+ & & 3 \\
\hline Volitivo & & 3 \\
\hline $\begin{array}{l}\text { Pragmático+/-, } \\
\text { hedónico-afectivo - }\end{array}$ \\
\hline
\end{tabular}

Fuente: Elaboración propia.

Existe una correspondencia entre las zonas modales más activadas por los encuestados y los valores presentes en los estereotipos identificados en los diccionarios (tabla 11). Esto permite establecer que el valor que los docentes asignan a sus representaciones de tarea escolar conserva los valores existentes en el protocolo semántico de esa entidad léxica. En ese orden de ideas, los valores pragmáticos positivos, los epistémicos, los deónticos y los 
intelectuales positivos. Por lo tanto, en los dos conjuntos de estereotipos predomina la idea de utilidad y esa característica se concentra en un saber, en un conocimiento que se obtiene con la realización de la tarea. A esto se agrega que las asociaciones de la tarea escolar activan valores ligados a la obligatoriedad, como se expuso anteriormente, y valores intelectuales presentes en el interés por los contenidos "vistos" en clase.

Es significativa la ausencia de valores hedónicoafectivos ambivalentes entre los estereotipos de las respuestas, lo que conduce a establecer que para los encuestados la posibilidad de generación de sentimientos de agrado, alegría, entusiasmo o sus contrarios, no son relevantes, pues solamente aparecen después de los valores aléticos (7) y orientados hacia el polo positivo (5). En este orden de ideas, prima la necesidad de la tarea, es decir, el valor ontológico, sobre los valores axiológicos positivos (hedónico-afectivos). Los docentes asumen entonces que las acciones ligadas a la tarea escolar generan solamente bienestar, entusiasmo, alegría y que no producen sentimientos negativos. Esto resalta si se tiene en cuenta que el contexto educativo de la ciudad de Bogotá es a menudo poblado por desazón y rechazo hacia las tareas, no necesariamente por la tarea misma, sino por su exceso, por la ausencia de objetivos o la falta de claridad de estos e incluso su seguimiento, entre otros.

Entre los valores restantes, activados significativamente, aparecen los ético-morales positivos y los finalizantes (volitivos) entre los docentes. Los encuestados se representan la tarea escolar como una oportunidad que se caracteriza por lo bueno, por lo adecuado para los estudiantes y se refuerza con la idea de voluntad y de intención. Se hace necesario preguntarse si la voluntad concierne al estudiante en su relación con la tarea, con la realización, o al docente y la asignación de la misma. Asimismo, parece importante analizar si la intención aparece en el sujeto a quien se le asigna a la tarea o en el actor que la impone. $\mathrm{Al}$ retomar los términos que contienen estos valores volitivos, se recuperan la consulta, la investigación y la dedicación. Pese a la escasa cantidad de valores finalizantes en estos estereotipos, se puede advertir que la voluntad se concreta en el estudiante, pero por asignación del docente. Esto significa que la intención no se genera en el individuo que realiza la tarea, sino que sería condicionada por el actor que la asigna.

\section{Cierre}

El estudio reveló que el grupo de 119 encuestados, docentes de lenguas de la educación básica y media de Bogotá, asocian una gama diversa y amplia de términos a la entidad léxica tarea escolar. Justamente, este número tan elevado de asociaciones denota una dispersión en los estereotipos vinculados a la palabra objeto de estudio en este trabajo. Ha de comprenderse que la diversidad no genera problemáticas, sino la débil relevancia de al menos un $90 \%$ de los términos asociados a la tarea. Estas representaciones lingüísticas comportan las concepciones, las creencias y, en principio, las acciones pedagógicas de los docentes. En ese aspecto se genera la dificultad: aunque el grupo encuestado active tantos y variados términos en relación con la tarea, no existe una suficiente unidad en la concepción de esta actividad tan importante en la formación, en el aprendizaje y en la enseñanza, especialmente en la educación básica y media.

Entre las representaciones preponderantes aparecen, a nivel del núcleo, la tarea como una actividad de refuerzo de un contenido visto y que se debe desarrollar en casa. En este orden de ideas, a diferencia del discurso lexicográfico, se restringe el espacio donde se realiza la actividad y se circunscribe a la casa lo que permite inferir que se desplaza una parte de la responsabilidad de los docentes a los padres o acudientes y actividades propias del salón de clase al domicilio de los estudiantes. De este modo, se liberan funciones docentes y se limitan los espacios en donde el sujeto podría llevar a cabo la multiplicidad de acciones relacionadas con la tarea escolar. Asimismo, el objeto del refuerzo se reduce a lo que el estudiante puede retomar en términos de contenidos, esto es: un saber declarativo, el componente enciclopédico de su aprendizaje. 
$\mathrm{Al}$ estudiar el conjunto variado de estereotipos relacionados con tarea escolar, los docentes ampliaron de manera significativa los que aparecen en el discurso lexicográfico, pero se generó una dispersión y la débil unidad de concepciones por la anunciada cantidad activada. Sobresalen algunas representaciones nuevas como consulta, investigación, autonomía, aprendizaje y obligación, labor, trabajo, entre otros. Con estos lexemas se aumentan los elementos a los que se asocia, en argumentación externa, la palabra tarea. Sin embargo, se reflejan algunas incoherencias entre las concepciones de los profesores y algunos debilitamientos tanto de elementos del núcleo como de los valores que estos activan al ser movilizados por estos encuestados. Se advierte la incongruencia entre autonomía y obligación/deber y las ambigüedades en torno a conocimiento, consulta e investigación. Igualmente, se observa en las representaciones de los docentes un afán por hacer repetir lo visto y por generar unos hábitos; no obstante, no se advierten elementos que permitan ver planeación, preparación, seguimiento, evaluación ni mejoramiento de las actividades ligadas a la tarea, ni la concepción misma de la tarea que tienen los estudiantes.

Por último, los docentes movilizan en sus representaciones de tarea escolar valores muy cercanos a los que circulan en los discursos lexicográficos. Prevalecen entonces los valores pragmáticos positivos, epistémicos, deónticos e intelectuales positivos que revelan el carácter de utilidad de la tarea escolar sobre todo cuando tiene como objeto el refuerzo de contenidos, del saber declarativo, logrado gracias a la obligatoriedad que deriva del docente que este último asume como interesante para el estudiante. Frente a estos, los docentes activan en sus ideas de la tarea valores aléticos que dan cuenta de la necesidad de las tareas y, en menor medida, valores hedónicoafectivos positivos y ausencia de hedónico-afectivos ambivalentes. Estos últimos valores sugieren que para los docentes la asignación de tareas a los estudiantes genera reacciones positivas como consecuencia de lo agradable, del bienestar que les generarían las actividades impuestas.

\section{Glosario}

Cinetismo: Se entiende como una transformación del significado léxico y su reconstrucción continua a través de mecanismos en la actuación discursiva.

Estereotipos lingüísticos: Conjuntos abiertos de asociaciones de elementos del núcleo con otras representaciones (lingüísticas). Estas asociaciones constituyen bloques de argumentación a partir de una relación causa-efecto, síntoma-fenómeno, finmedio, etc. Es la parte evolutiva del significado.

Núcleo: Es la parte estable, definida, del significado léxico de una palabra.

Posibles argumentativos: Secuencias discursivas que asocian una palabra con uno o varios de sus estereotipos y son calculables, analizables a partir de los estereotipos.

Representación lingüística: Forma modal (término, palabra) que un hablante asocia con otras formas modales.

\section{Semántica de los Posibles Argumentativos} (SPA): Teoría semántica fundada sobre la base de la semántica léxica, la semántica textual, el análisis del discurso y el análisis lingüístico del discurso. Este modelo teórico describe y analiza el significado léxico con base en el presupuesto de que el significado de las entidades léxicas (palabras) es compartido por los hablantes de una comunidad lingüística. La SPA se presenta como una teoría que da cuenta del nivel de inscripción del valor axiológico en el significado de las palabras.

Significado léxico: Representaciones asociadas a una expresión verbal de manera permanente en una comunidad lingüística.

Valores modales: Tomas de posición, actitudes que el hablante asume frente al contenido proposicional de su enunciado. Estos valores están contenidos en las formas modales (palabras). En el marco teórico de referencia se clasifican como ontológicos (deónticos y aléticos), de juicio de verdad (epistémicos y doxológicos), axiológicos (éticos, morales, pragmáticos, intelectuales, estéticos, hedónicos, afectivos) y finalizantes (volitivos y desiderativos). 


\section{Referencias}

Carel, M., y Ducrot, O. (1999). Le problème du paradoxe dans une sémantique argumentative. Langue française, 123, 6-26.

Carel, M., y Ducrot, O. (2005). La semántica argumentativa: una introducción a la teoría de los bloques semánticos. Buenos Aires: Colihue Universidad.

Castillo, M., Ruiz, J., y Santiago, A. (2014). La representación del significado léxico y la movilización de valores sociales: la tarea escolar. Folios, 40, 105-124.

Galatanu, O. (2003). La sémantique des possibles argumentatifs et ses enjeux pour l'analyse du discours. $E l$ texto como encrucijada: estudios franceses y francófonos, 2, 213-226.

Galatanu, O. (2003a). La construction discursive des valeurs. En J.-M. Barbier (Dir.), Valeurs et activités professionnelles. Séminaire du Centre de Recherche sur la Formation du CNAM (pp. 87-114). Paris: L'Harmattan.

Galatanu, O. (2004). La sémantique des possibles argumentatifs et ses enjeux pour l'analyse du discours. En Actes du colloque international deetudes françaises. $\mathrm{La}$ Rioja: Université de La Rioja.

Galatanu, O. (2005). Analyse du discours. Diversité Ville, école, intégration, 140, 55-61. Disponible en http:// www.cndp.fr/archivage/valid/70174/70174-1077813726.pdf

Galatanu, O. (2006). Le cinétisme de la signification lexicale. En J.-M. Barbier y M. Durand (Ed.), Sujets, activité, environnement. Paris: Presses Universitaires de France.
Galatanu, O. (2006a). La construction discursive des représentations de la langue française et de la culture françaises chez les futurs enseignants du FLE. En Synergies Pologne(2) (pp. 185-195).

Galatanu, O. (2007). Sémantique des possibles argumentatifs et axiologisation discursive. En Bouchard, J. Evrard (Ed.), Représentation du sens linguistique 2 (pp. 313-325). Louvain-La-Neuve: Duculot de Boeck.

Galatanu, O. (2009). L'Analyse du Discours dans la perspective de la Sémantique des Possibles Argumentatifs: les mécanismes sémantico-discursifs de construction du sens et de reconstruction de la signification lexicale. En Cahiers du Laboratoire de Recherche sur le Langage, (2), 49-68.

Galatanu, O., y Nikolenko, V. (2009). Acquisition du lexique de la zone sémantique de l'axiologique: Le cas des apprenants avancés. En O. Galatanu, M. Pierrard, D. Van Raemdonck (Dir.), Construction $d u$ sens et acquisition de la signification linguistique dans l'interaction (pp. 319-332). Bruxelles: P.I.E. Peter Lang.

Larousse (2007). El pequeño Larousse ilustrado [13. ${ }^{\mathrm{a}}$ edición]. México: Ediciones Larousse.

Martínez, F. (2002). El cuestionario. Un instrumento para la investigación en las ciencias sociales. Barcelona: Laertes.

Meirieu, P. (2005). Los deberes en casa. Barcelona: Octaedro.

Moliner, M. (2008). Diccionario de uso del español [3. ${ }^{\mathrm{a}}$ edición]. Barcelona: Editorial Gredos.

Real Academia Española (RAE) (2003). Diccionario de la lengua española [Vigésima segunda edición. Edición electrónica Versión 1.0]. Madrid: Espasa Calpe. 